\title{
Usefulness of a short training seminar on how to handle difficult patients in simulated education
}

This article was published in the following Dove Press journal:

Advances in Medical Education and Practice

Kiyoshi Shikino',2
Shoichi Ito ${ }^{2,3}$
Yoshiyuki Ohira'
Kazutaka Noda'
Mayumi Asahina ${ }^{2,3}$
Masatomi Ikusaka ${ }^{1,2}$
'Department of General Medicine, Chiba
University Hospital, Chiba, Japan; ${ }^{2}$ Health
Professional Development Center, Chiba
University Hospital, Chiba, Japan; ${ }^{3}$ Office
of Medical Education, Chiba University
Graduate School of Medicine, Chiba,
Japan
Japan
Correspondence: Kiyoshi Shikino Department of General Medicine, Chiba University Hospital, I-8-I, Inohana,

Chuo-ku, Chiba, Japan

Tel +8I 43222 7I7I (Ext. 6438);

$+8 \mid 432244758$

Fax +8I 432244758

Email kshikino@gmail.com
Objective: To evaluate a short-time simulation training seminar on how to handle difficult patients using professional simulated patients (SPs) such as actors.

Participants: Sixty-three second-year residents at Chiba University Hospital between 2015 and 2017 who only attended the seminar once.

Intervention: The participants were divided into small groups, each of which was assigned a supervisory doctor as facilitator. Those who were playing the doctor's role enacted a medical interview with an SP. After the interview, the facilitator, the SP, and the observing residents participated in a debriefing while watching a recorded video of the interview.

Outcome measures: Pre- and post-seminar questionnaires using a 7-point Likert scale (from 1: strongly disagree to 7: strongly agree) were used to examine the differences in "confidence in ability to handle difficult patients" and "learning motivation to handle difficult patients". The two items examined by both pre- and post-seminar questionnaires, were analyzed by a paired $t$-test. The residents were also surveyed on their satisfaction with the seminar, acquisition of new knowledge, and impressions and comments (free-text answers). Results: The findings of the questionnaire showed a significant post-seminar increase in confidence $(3.1 \pm 1.6$ to $4.0 \pm 1.5[p<0.01])$ and learning motivation $(5.3 \pm 1.8$ to $5.8 \pm 1.5$ $[p<0.01])$ as well as high levels of satisfaction $(5.8 \pm 1.1)$ with the seminar and acquisition of knowledge $(5.7 \pm 1.3)$. Some residents further reported that the seminar led to self-review and was valuable for their future clinical practice.

Conclusion: Our seminar on how to handle difficult patients was perceived as effective, as evaluated by the questionnaire, despite the short duration of the session. Factors potentially contributing to this effectiveness include the use of actors as SPs and the post-interview debriefing with feedback from the SP, colleagues, and facilitator.

Keywords: difficult patient encounter, simulation scenario, simulated patient, medical education, short training seminar

\section{Introduction}

Difficult patients are defined as those who elicit strong negative emotions from their physicians. ${ }^{1}$ Studies conducted in the primary care setting reported that difficult patients accounted for about $15 \%$ of all outpatients. ${ }^{2,3}$ The handling of difficult patients involves many issues in the context of clinical practice and interferes with the original therapeutic goals. ${ }^{3,4}$ Difficult patients often have depression, anxiety disorder, poor physical function, unfulfilled demands, unsatisfactory personal circumstances, somatized symptoms, or severe symptoms. ${ }^{2}$ In addition, difficult patients compel their physicians to give them an explanation, tests, and treatment for their somatized symptoms or excessive demands, eventually causing fatigue, stress, and burnout in the physicians, resulting in markedly decreased job 
satisfaction. ${ }^{5}$ On the other hand, patients not only show a low degree of patient satisfaction 2 weeks after medical examination but also tend to feel that their symptoms have worsened. Because of this, the frequency of visits to medical facilities tends to increase, ${ }^{6}$ raising the cost of health care. Thus, difficult patients exert an influence on physicians that is disadvantageous to the patients themselves as well as to health economics.

Under the current circumstances of aiming to improve the quality of patient-centered health care, the ability of health care providers to have good communication with difficult patients is essential for its realization. Factors relating to difficult patients include patient factors, physician factors, and environmental factors, ${ }^{6}$ and it has been emphasized that physicians' perception of difficult patients does not depend on the patients' issues alone. ${ }^{7}$ When handing difficult patients, it is important to non-judgmentally understand the reality of difficult patients and analyze the factors affecting difficult patients in order to build good patient-physician relationships and practice appropriate patient care. $^{8,9}$

The lack of clinical experience of physicians is cited as a factor in the physicians' perception of difficult patients. ${ }^{8}$ It is, therefore, necessary for residents to be trained how to handle difficult patients. Although residents teach themselves how to deal with difficult patients through contact with various patients in the setting of clinical practice, experience with difficult patients varies among them. Physicians often have to deal with difficult patients under difficult circumstances, such as on a one-on-one basis in the absence of support from others, whereby opportunities to obtain feedback from supervisory doctors are limited. To solve these issues, we turned our attention to simulation education, which allows trainees to experience various simulated types of patients under safe conditions.

Although seminars on how to handle difficult patients have recently become available, there have been only a limited number of reports on the usefulness of seminars on difficult patient management, particularly using simulation education. ${ }^{10-14}$ With regards to seminar duration, previously reported seminars lasted 4.5 hours to 2.5 days, ${ }^{11,15-17}$ which presumably placed a considerable burden on both supervisory doctors and participants. The Health Professional Development Center at Chiba University Hospital has been providing residents with simulation education since 2012 in the form of relatively short seminars aimed at acquiring the competence to handle the difficult kind of patients who might be encountered in the clinical practice setting. Our research question is whether the seminar on how to handle difficult patients using simulated patients (SPs) is useful for increasing learning motivation and acquisition of the skills required to handle difficult patients even when the duration of the seminar is short.

\section{Methods}

\section{Procedure}

This study was conducted with approval from the Ethical Review Board of the Graduate School of Medicine and School of Medicine, Chiba University. In the informed consent procedure, all possible participants were informed about the study and gave their written consent to participate voluntarily on the basis of an adequate understanding of its goals and procedures.

\section{Participants}

The participants were all second-year residents at Chiba University Hospital (63 individuals comprising 45 men and 18 women, with a mean age of $27.5 \pm 1.8$ years). We conducted the seminar nine times between 2015 and 2017, of which the participants only attended the seminar once. The implementation of the seminar was scheduled toward the end of the 2-year clinical training of residents at a time when they might already have experienced medical interview with difficult patients.

The participants were divided into small groups of three to four individuals, each of which had a supervisory doctor as facilitator. The facilitators were three male teachers who had graduated from medical school at an average of 13 years prior to the study. They belonged to the Health Professional Development Center, Chiba University Hospital and had gained previous teaching experience in terms of how to handle difficult patients. Each seminar session took about 2 hours per group.

\section{Briefing}

Before the medical interview, the facilitators gave a briefing to the participants. In the briefing, the facilitators explained to the participants the objectives of the seminar, expectations, and roles in 5 minutes. A questionnaire was used with a 7-point Likert scale (from 1: strongly disagree to 7: strongly agree) concerning the participants' "confidence in ability to handle difficult patients" and "learning motivation to handle difficult patients". Roles were rotated among participants (the doctor role and the observer role) per scenario to allow each of them to play the doctor role. Each participant chose one scenario that he or she wanted 
to perform from among four different scenarios that were presented to them. After the participant was given a written explanation of the relevant circumstances of the simulation and understood the task, the scenario was started.

\section{Scenarios and characters}

The following four scenarios were used:

1. a patient consistently rejects receiving the necessary tests (self-defense, fear).

2. A patient is very angry about the poor attitude of each department in the hospital (quick to resent).

3. A patient demands explanation, testing, and treatment for a very rare disease he or she heard about from a media report, etc (presence of mental disease or personality disorder).

4. A mother is upset about the sudden death of her child (grief, bad news).

The scenarios were prepared based on focus group discussions and the results of free-text questionnaires and individual interviews of participants in seminars on the handling of difficult patients conducted between 2012 and 2014. Experienced persons (participants in SP training sessions, actors, etc) were recruited as collaborators to play SPs in the seminar.

\section{Learner encounter}

The participant who played the doctor's role had a medical interview with an SP. The participant-observer and the facilitator observed the interview in real time through a monitor set in a separate room. The content of the medical interview was video-recorded to review it during debriefing. The time-out of the medical interview was indicated by the facilitator when he judged that there would be no additional progression made in the medical interview. The time required by the participants for the medical interview was determined from the recorded data.

\section{Debriefing}

Feedback was provided by the facilitator, the SP, and the participant who took on the role of observer while watching the recorded video. They held a debriefing of about 15 minutes with the participant who had assumed the doctor's role, using the analysis summarization method. ${ }^{18}$ A postseminar questionnaire was used after the debriefing. The questionnaire used the free-text method and a 7-point Likert scale (from 1: strongly disagree to 7: strongly agree). The investigated items were "confident in the ability to handle difficult patients", "motivated to learn how to handle difficult patients", "satisfied with seminar", "acquired new knowledge", "high performance of the SP", and "duration of seminar (from 1: very short to 7: very long)". These questionnaires were developed based on focus group discussions and the results of seminars on the handling of difficult patients conducted between 2012 and 2014.

\section{Main measures}

To evaluate the usefulness of the seminar, "confidence in ability to handle difficult patients" and "learning motivation to handle difficult patients" were rated by a pre- and post-seminar questionnaire using a 7-point Likert scale (Tables 1 and 2). Similarly, "satisfaction with seminar", "acquisition of new knowledge", "performance of the SP", and "duration of seminar" were rated by post-seminar questionnaire using a 7-point Likert scale. Participants were also requested to write freely about their impressions and comment on the seminar.

\section{Statistical analyses}

All statistical analyses were conducted using SPSS Statistics for Windows 22.0 (IBM Corporation, Armonk, NY, USA). The level of significance was less than $5 \%$ in each analysis. "Confidence in ability to handle difficult patients" and "learning motivation to handle difficult patients", the two items examined by both pre- and postseminar questionnaires, were analyzed by a paired $t$-test. The sample size was considered 61 participants.

Table I Pre-seminar questionnaire items

\begin{tabular}{|l|}
\hline Pre-seminar \\
\hline I) You have confidence in your ability to handle difficult patients. \\
2) You have learning motivation to handle difficult patients. \\
\hline
\end{tabular}

Note: According to the 7-point Likert scale.

Table 2 Post-seminar questionnaire items

Post-seminar
1) You have confidence in your ability to handle difficult patients.
2) You have learning motivation to handle difficult patients.
3) Satisfied with the seminar.
4) You have acquired new knowledge.
5) Performance of the simulated patient.
6) Duration of the seminar.
7) Impressions and comments on the seminar.

Notes: The 7-point Likert scale was used for items 1-6. A free-text section was allocated for item 7). 


\section{Patient and public involvement}

Patients were not involved in this study.

\section{Results}

The mean age of the participants was 28 years (26-34), of which $72 \%$ were men. Data were obtained from all three seminar sessions (response recovery rate $100 \%$, valid response rate $100 \%$ ) (Table S1). The mean time required for one session of the medical interview was $7.5 \pm 2.8$ minutes.

The mean score for "confidence in ability to handle difficult patients" was increased from $3.1 \pm 1.6$ before the seminar to $4.0 \pm 1.5$ after the seminar $(p<0.01)$ (Figure 1, Table 3). The mean score for "learning motivation to handle difficult patients" was increased from $5.3 \pm 1.8$ before the seminar to $5.8 \pm 1.5$ after the seminar $(p<0.01)$ (Figure 2, Table 3). There were two participants who showed decreased confidence in ability to handle difficult patients, as well as nine participants who showed decreased "learning motivation to handle difficult patients".

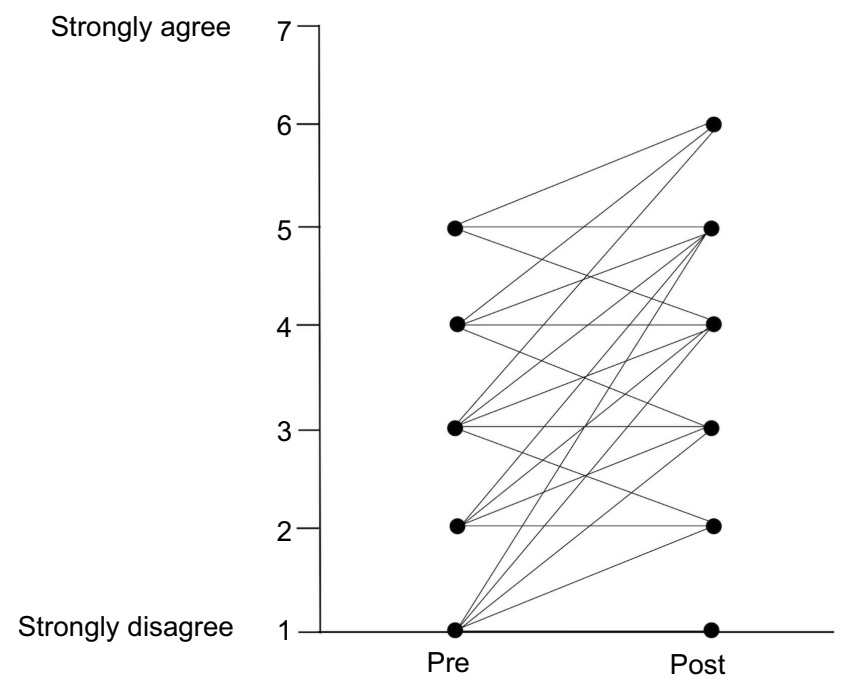

Figure I Pre- and post-seminar mean self-assessment scores on confidence in ability to handle difficult patients are shown. The mean score on "confidence in ability to handle difficult patients" increased from $3.1 \pm 1.6$ before the seminar to 4.0 \pm 1.5 after the seminar $(p<0.01)$.
The questionnaire conducted after the seminar revealed that "satisfaction with seminar" was rated as $5.8 \pm 1.1$ on average, and that $58(92.1 \%)$ of the 63 participants gave a score of 5 or higher on the 7-point Likert scale. The mean score of "acquisition of new knowledge" was $5.7 \pm 1.3$, and 57 $(90.5 \%)$ of the 63 participants gave a score of 5 or higher on the 7-point Likert scale. There were no negative comments corresponding to a Likert score of 3 or lower for any of the items examined. The mean score of "performance of the SP" was $6.1 \pm 1.5$ (from 1: very unnatural to 7 : extremely natural). The mean score of "duration of the entire seminar" was 4.0 \pm 1.1 (from 1: very short to 7 : very long).

As for "impressions and comments on the seminar" (free-text), some respondents reported, as follows:

1. "I was able to review my own drawbacks."

2. "I could take advantage of the seminar in future clinical practice."

3. "I think it's useful to observe colleagues' medical interviews."

4. "I became less confident because my own drawbacks became apparent through comparison with the others' medical interviews."

5. "I think that the comments from SPs were convincing."

\section{Discussion}

The seminar on how to handle difficult patients was highly appreciated by the participating residents. There was a significant improvement perceived in "confidence in ability to handle difficult patients" and "learning motivation to handle difficult patients" after the seminar in comparison with before the seminar. In addition, over $90 \%$ of participants gave a score of 5 or higher on the 7-point Likert scale for both "satisfaction with the seminar" and "acquisition of new knowledge", showing that this seminar was satisfactory and allowed participants to acquire new knowledge. The training's effectiveness was generally evaluated with Kirkpatrick's levels for measuring

Table 3 Outcomes: confidence in ability to handle difficult patients and learning motivation to handle difficult patients

\begin{tabular}{|l|l|l|l|}
\hline \multicolumn{2}{|l|}{} & $\begin{array}{l}\text { Participants } \\
(n=63)\end{array}$ & $\begin{array}{l}\text { Post-test } \\
\text { mean (SD) }\end{array}$ \\
\cline { 2 - 4 } & $\begin{array}{l}\text { Pre-test } \\
\text { mean (SD) }\end{array}$ & $\begin{array}{l}4.0(1.5) \\
5.8(1.5)\end{array}$ \\
\hline $\begin{array}{l}\text { Confidence in ability to handle difficult patients* } \\
\text { Learning motivation to handle difficult patients* }\end{array}$ & $\begin{array}{l}3.1(\mathrm{I}) \\
5.3(\mathrm{I})\end{array}$ & $\begin{array}{l}<0.01 \\
<0.01\end{array}$ \\
\hline
\end{tabular}

Note: *I: strongly disagree, 7: strongly agree. 


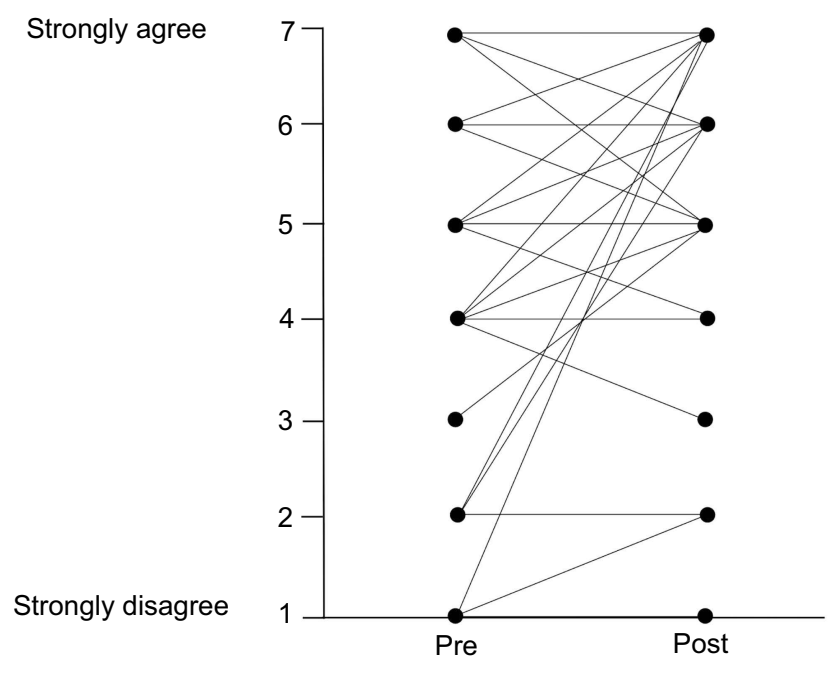

Figure 2 Pre- and post-seminar mean self-assessment scores on learning motivation to handle difficult patients are shown. The mean score on "learning motivation to handle difficult patients" increased from $5.3 \pm 1.8$ before the seminar to $5.8 \pm 1.5$ after the seminar $(p<0.01)$.

training effectiveness. ${ }^{19,20}$ This seminar had an influence on Level 1 and Level 2 of Kirkpatrick's scale of evaluation. Reaction in Level 1 corresponded to "satisfaction with the seminar", and learning in Level 2 corresponded to "confidence in ability to handle difficult patients" and "acquisition of new knowledge".

A characteristic feature of this seminar is its duration, which was basically 2 hours, which was shorter than that of similar seminars conducted at other institutions; and yet, it achieved favorable training efficacy. The reasons that this seminar was useful are cited below.

\section{The seminar used professional SPs}

Although it is reported that using SPs in simulation education enhances reality and improves the quality of education, ${ }^{21}$ the role of SPs in previous reports were played by health care providers themselves. As expression of feelings is at the core of difficult patients' behaviors, we thought that simulation using actors, who were expected to be superior in this aspect, would be more meaningful. Therefore, we used actors and experts who were trained in acting as SPs. In fact, their performance was rated by the participating residents as $6.1 \pm 1.5$ on average on the 7-point Likert scale, suggesting that they gave a highly realistic performance.

\section{The seminar was conducted at around the end of residency}

The pre-seminar questionnaire showed high "learning motivation to handle difficult patients" (with a mean score of 5.3 \pm 1.8 on the 7-point Likert scale). According to adult learning theory, education has a higher learning effect when it is implemented at a time of increased motivation of the learner, ie, when there is readiness on the part of the learner. ${ }^{22}$ On the other hand, students and residents in the early stage of residency may not be fully aware of the motivation for learning because of limited clinical experience, and experienced physicians are likely to have already acquired the ability to handle difficult patients. In this study, the subjects were restricted to residents shortly before completion of basic clinical training, and thus the seminar achieved high efficacy and gave a feeling of high satisfaction to the participants.

\section{Time-out was indicated by the facilitator who was monitoring the interview}

The medical interview was continued until the facilitator, who was observing the interview through the monitor set in a separate room, judged that there would be no progression in the interview. This was because the time required for medical interviewing of difficult patients would vary according to the participant, the SP, or scenario. If the duration of the medical interview is too short, clinical experience with difficult patients will be lacking; in contrast, if the medical interview is too long, the efficiency of the seminar will be decreased. To regulate the time of the encounter with difficult patients, the indication of time-out by the facilitator was considered to be useful. According to the participant questionnaire, the time of the seminar was rated as $4.0 \pm 1.1$ on average (from $1=$ very short to $7=$ very long), and the time of the seminar was appropriate as a whole.

\section{Debriefing was conducted by the SP, observer, and facilitator}

Debriefing can facilitate the learner's self-review ${ }^{23}$ and is one of the most important factors of simulation-based learning. ${ }^{24,25}$ As a factor that increases self-review, feedback while watching the recorded video is useful. ${ }^{26}$ Furthermore, the recorded video can be used in other seminars and lead to improvement of scenarios in the future. The participant serving as the observer enables useful review of the interview through detached observation of how to handle difficult patients. As a result, the participant is able to experience multiple scenarios within a short time. In addition, debriefing allows for the sharing of experience with colleagues. The participant can therefore experience decreased frustration and learn new ways of handling difficult patients. If improvement to a level that allows self-review is achieved based on adult learning 
theory, it is presumed that physicians can build a good patient-physician relationship by performing self-review during or after the examination of patients.

\section{Limitations}

This study has two limitations. One is that the behavior corresponding to Level 3 and the results in Level 4 of Kirkpatrick's framework for measuring training effectiveness have not been measured yet. However, it is probable that a training effect corresponding to Level 3 can be confirmed by continuous observation because "learning motivation to handle difficult patients" was increased; moreover, some participants reported in the free-text section that they were able to review their own drawbacks or wanted to make use of the learning from the seminar in future clinical practice. It would be valuable to evaluate the Level 4 effect by holding similar seminars continuously and conducting a follow-up survey of participants.

The other limitation is that there were a few participants who showed decreased "confidence in ability to handle difficult patients", as well as participants who showed decreased "learning motivation to handle difficult patients". The participants who had a decreased score of "confidence in ability to handle difficult patients" reported in the free-text section that they noticed their own drawbacks from a comparison with others' medical interviews. Because this participant's score of "learning motivation to handle difficult patients" was as high as 7, it is apparent that this seminar induced behavior modification toward the further learning of how to handle difficult patients, despite the decreased confidence level. Nine participants showed a decreased score of "learning motivation to handle difficult patients" in the postseminar questionnaire. It is possible that the seminar decreased their interest in how to handle difficult patients possibly because they have less need for handling difficult patients according to their medical specialty in the near future. It is necessary for future data collection to determine the decreased "learning motivation to handle difficult patients" by means of additional questionnaire items, post-seminar interviews, etc. For these participants who are less confident, giving them successful experience of handling difficult patients by additional repeated practice of the same scenario may be effective to increase their "learning motivation to handle difficult patients".

\section{Conclusion}

The seminar on how to handle difficult patients using SPs was perceived as useful, as established by the questionnaire, for increasing learning motivation and the acquisition of skills required to handle difficult patients when the duration of the seminar is not redundant. The possible factors supporting the effectiveness of the seminar despite its short duration include the use of professional SPs, implementation of the seminar toward the end of residency when there was high motivation for learning, indication of time-out by the facilitator who was monitoring the interview, and debriefing from the SP, colleagues, and facilitator. It is further necessary to confirm the usefulness of the seminar by its continuous implementation and a follow-up survey of participants.

\section{Author contributions}

All authors contributed to data analysis, drafting and revising the article, gave final approval of the version to be published, and agree to be accountable for all aspects of the work.

\section{Disclosure}

The authors report no conflicts of interest in this work.

\section{References}

1. Groves JE. Taking care of the hateful patient. $N$ Engl J Med. 1978;298:883-887. doi:10.1056/NEJM197804202981605

2. Jackson JL, Kroenke K. Difficult patient encounters in the ambulatory clinic: clinical predictors and outcomes. Arch Intern Med. 1999;159:1069-1075.

3. Hahn SR. Physical symptoms and physician-experienced difficulty in the physician-patient relationship. Ann Intern Med. 2001;134:897904.

4. Hull SK, Broquet K. How to manage difficult patient encounters. Fam Pract Manag. 2007;14:30-34.

5. An PG, Rabatin JS, Manwell LB, Linzer M, Brown RL, Schwartz MD. Burden of difficult encounters in primary care: data from the minimizing error, maximizing outcomes study. Arch Intern Med. 2009;169:410-414. doi:10.1001/archinternmed.2008.549

6. Haas LJ, Leiser JP, Magill MK, Sanyer ON. Management of the difficult patient. Am Fam Physician. 2005;72:2063-2068.

7. Hinchey SA, Jackson JL. A cohort study assessing difficult patient encounters in a walk-in primary care clinic, predictors and outcomes. $J$ Gen Intern Med. 2011;26:588-594. doi:10.1007/s11606-010$1620-6$

8. Steinmetz D, Tabenkin H. The 'difficult patient' as perceived by family physicians. Fam Pract. 2001;18:495-500. doi:10.1093/fampra/18.5.495

9. Smith RC, Lyles JS, Gardiner JC, et al. Primary care clinicians treat patients with medically unexplained symptoms: a randomized controlled trial. J Gen Intern Med. 2006;21:671-677. doi:10.1111/j.15251497.2006.00460.x

10. Martin EB Jr, Mazzola NM, Brandano J, Luff D, Zurakowski D, Meyer EC. Clinicians' recognition and management of emotions during difficult healthcare conversations. Patient Educ Couns. 2015;98:1248-1254. doi:10.1016/j.pec.2015.07.031

11. Renouf T, Mitchell K, Hollett S, Angus K, Dubrowski A. Deteriorating patient scenario for simulation-based training of difficult patient encounters in the emergency room. Cureus. 2014;6:e192. 
12. Bressmann T, Eriks-Brophy A. Use of simulated patients for a student learning experience on managing difficult patient behaviour in speech-language pathology contexts. Int J Speech Lang Pathol. 2012;14:165-173. doi:10.3109/17549507.2011.638727

13. Marken PA, Zimmerman C, Kennedy C, Schremmer R, Smith KV. Human simulators and standardized patients to teach difficult conversations to interprofessional health care teams. Am J Pharm Educ. 2010;74:120. doi:10.5688/aj7407120

14. Boendermaker PM, Faber V, Weijmar Schultz WC. Dealing with difficult sexual questions during consultations: a new training program. J Psychosom Obstet Gynaecol. 2008;29:79-82. doi:10.1080/ 01674820802095707

15. Levinson W, Roter D. The effects of two continuing medical education programs on communication skills of practicing primary care physicians. $J$ Gen Intern Med. 1993;8:318-324. doi:10.1007/bf02600146

16. Roter DL, Hall JA, Kern DE, Barker LR, Cole KA, Roca RP. Improving physicians' interviewing skills and reducing patients' emotional distress: a randomized clinical trial. Arch Intern Med. 1995; 155:1877-1884.

17. Joos SK, Hickam DH, Gordon GH, Baker LH. Effects of a physician communication intervention on patient care outcomes. J Gen Intern Med. 1996;11:147-155. doi:10.1007/bf02600266

18. Levine AI, DeMaria S Jr., Schwartz AD, Sim AJ. The Comprehensive Textbook of Healthcare Simulation. New York: Springer; 2013.

19. Kirkpatrick D, Kirkpatrick J. Evaluating Training Programs. 3rd ed. The four levels. San Francisco: Berrett-Koehler;2006.
20. Hultman CS, Halvorson EG, Kaye D, et al. Sometimes you can't make it on your own: the impact of a professionalism curriculum on the attitudes, knowledge, and behaviors of an academic plastic surgery practice. J Surg Res. 2013;180:8-14. doi:10.1016/j. jss.2012.11.029

21. Bradley P. The history of simulation in medical education and possible future directions. Med Educ. 2006;40:254-262. doi:10.1111/ j.1365-2929.2006.02394.x

22. Knowles MS. Self-Directed Learning: A Guide for Learners and Teachers. 1st ed. New York: Cambridge Book Co.; 1975.

23. Brydges R, Nair P, Ma I, Shanks D, Hatala R. Directed self-regulated learning versus instructor-regulated learning in simulation training. Med Educ. 2012;46:648-656. doi:10.1111/j.1365-2923.2012.04268.x

24. Issenberg SB, McGaghie WC, Petrusa ER, Lee Gordon D, Scalese RJ. Features and uses of high-fidelity medical simulations that lead to effective learnig: a BEME systematic review. Med Teach. 2005;27:10-28. doi:10.1080/01421590500046924

25. Fanning RM, Gaba DM. The role of debriefing in simulation-based learning. Simul Healthc. 2007;2:115-125. doi:10.1097/ SIH.0b013e3180315539

26. Seif GA, Brown D. Video-recorded simulated patient interactions: can they help develop clinical and communication skills in today's learning environment? J Allied Health. 2013;42:e37-e44. 


\section{Supplementary materials}

Table SI Questionnaire results

\begin{tabular}{|c|c|c|c|c|}
\hline $\begin{array}{l}\text { Participants' } \\
\text { number }\end{array}$ & $\begin{array}{l}\text { Confidence in ability to handle diffi- } \\
\text { cult patients (pre-/post-seminar) }\end{array}$ & $\begin{array}{l}\text { Learning motivation to handle diffi- } \\
\text { cult patients (pre-/post-seminar) }\end{array}$ & $\begin{array}{l}\text { Satisfaction } \\
\text { with the } \\
\text { seminar }\end{array}$ & $\begin{array}{l}\text { Acquisition of } \\
\text { new knowledge }\end{array}$ \\
\hline 1 & $\mathrm{I} / \mathrm{I}$ & $5 / 5$ & 4 & 4 \\
\hline 2 & $5 / 1$ & $7 / 6$ & 7 & 7 \\
\hline 3 & $\mathrm{I} / 2$ & $5 / 5$ & 5 & 5 \\
\hline 4 & $2 / 2$ & $4 / 5$ & 5 & 5 \\
\hline 5 & $2 / 2$ & $6 / 5$ & 5 & 5 \\
\hline 6 & $2 / 2$ & $7 / 6$ & 6 & 5 \\
\hline 7 & $3 / 2$ & $6 / 6$ & 5 & 5 \\
\hline 8 & $3 / 2$ & $6 / 6$ & 6 & 5 \\
\hline 9 & $1 / 3$ & $7 / 6$ & 6 & 6 \\
\hline 10 & $1 / 3$ & $2 / 7$ & 7 & 6 \\
\hline 11 & $2 / 3$ & $6 / 5$ & 5 & 5 \\
\hline 12 & $3 / 3$ & $2 / 6$ & 5 & 4 \\
\hline 13 & $3 / 3$ & $6 / 6$ & 6 & 5 \\
\hline 14 & $3 / 3$ & $7 / 7$ & 6 & 6 \\
\hline 15 & $4 / 3$ & $2 / 2$ & 5 & 4 \\
\hline 16 & $4 / 3$ & $4 / 3$ & 5 & 5 \\
\hline 17 & $4 / 3$ & $6 / 7$ & 7 & 6 \\
\hline 18 & $4 / 3$ & $7 / 7$ & 6 & 5 \\
\hline 19 & $4 / 3$ & $7 / 7$ & 7 & 6 \\
\hline 20 & $1 / 4$ & $5 / 6$ & 6 & 5 \\
\hline 21 & $\mathrm{I} / 4$ & $7 / 7$ & 7 & 7 \\
\hline 22 & $2 / 4$ & $4 / 5$ & 5 & 5 \\
\hline 23 & $2 / 4$ & $6 / 5$ & 5 & 6 \\
\hline 24 & $2 / 4$ & $6 / 7$ & 7 & 7 \\
\hline 25 & $2 / 4$ & $7 / 7$ & 7 & 7 \\
\hline 26 & $3 / 4$ & $5 / 5$ & 5 & 5 \\
\hline 27 & $3 / 4$ & $5 / 5$ & 7 & 7 \\
\hline 28 & $3 / 4$ & $5 / 6$ & 5 & 5 \\
\hline 29 & $3 / 4$ & $5 / 6$ & 5 & 7 \\
\hline 30 & $3 / 4$ & $5 / 6$ & 6 & 5 \\
\hline 31 & $3 / 4$ & $5 / 6$ & 6 & 6 \\
\hline 32 & $3 / 4$ & $7 / 7$ & 7 & 6 \\
\hline 33 & $4 / 4$ & $4 / 4$ & 4 & 4 \\
\hline 34 & $4 / 4$ & $6 / 5$ & 6 & 6 \\
\hline 35 & $4 / 4$ & $4 / 6$ & 6 & 6 \\
\hline 36 & $4 / 4$ & $6 / 6$ & 4 & 3 \\
\hline 37 & $4 / 4$ & $4 / 7$ & 7 & 7 \\
\hline 38 & $4 / 4$ & $6 / 7$ & 6 & 7 \\
\hline 39 & $5 / 4$ & $5 / 4$ & 4 & 4 \\
\hline 40 & $\mathrm{I} / 5$ & $3 / 5$ & 6 & 7 \\
\hline 41 & $\mathrm{I} / 5$ & $5 / 5$ & 6 & 6 \\
\hline 42 & $2 / 5$ & $5 / 6$ & 6 & 6 \\
\hline 43 & $2 / 5$ & $5 / 7$ & 6 & 5 \\
\hline 44 & $2 / 5$ & $7 / 7$ & 6 & 6 \\
\hline 45 & $2 / 5$ & $7 / 7$ & 6 & 7 \\
\hline 46 & $2 / 5$ & $7 / 7$ & 7 & 7 \\
\hline
\end{tabular}


Table SI (Continued).

\begin{tabular}{|c|c|c|c|c|}
\hline $\begin{array}{l}\text { Participants' } \\
\text { number }\end{array}$ & $\begin{array}{l}\text { Confidence in ability to handle diffi- } \\
\text { cult patients (pre-/post-seminar) }\end{array}$ & $\begin{array}{l}\text { Learning motivation to handle diffi- } \\
\text { cult patients (pre-/post-seminar) }\end{array}$ & $\begin{array}{l}\text { Satisfaction } \\
\text { with the } \\
\text { seminar }\end{array}$ & $\begin{array}{l}\text { Acquisition of } \\
\text { new knowledge }\end{array}$ \\
\hline 47 & $3 / 5$ & $6 / 6$ & 7 & 7 \\
\hline 48 & $3 / 5$ & $5 / 7$ & 7 & 7 \\
\hline 49 & $4 / 5$ & $3 / 5$ & 4 & 6 \\
\hline 50 & $4 / 5$ & $4 / 5$ & 5 & 5 \\
\hline 51 & $4 / 5$ & $6 / 6$ & 5 & 6 \\
\hline 52 & $5 / 5$ & $5 / 6$ & 6 & 5 \\
\hline 53 & $5 / 5$ & $5 / 6$ & 6 & 7 \\
\hline 54 & $5 / 5$ & $6 / 6$ & 5 & 5 \\
\hline 55 & $5 / 5$ & $6 / 6$ & 6 & 5 \\
\hline 56 & $5 / 5$ & $6 / 6$ & 6 & 6 \\
\hline 57 & $5 / 5$ & $5 / 7$ & 7 & 7 \\
\hline 58 & $5 / 5$ & $7 / 7$ & 6 & 6 \\
\hline 59 & $3 / 6$ & $5 / 6$ & 6 & 5 \\
\hline 60 & $4 / 6$ & $6 / 6$ & 6 & 7 \\
\hline 61 & $4 / 6$ & $7 / 7$ & 7 & 7 \\
\hline 62 & $5 / 6$ & $1 / 2$ & 6 & 5 \\
\hline 63 & $5 / 6$ & $7 / 5$ & 6 & 6 \\
\hline Average & $3.1 / 4.0$ & $5.3 / 5.8$ & 5.8 & 5.7 \\
\hline
\end{tabular}

\section{Publish your work in this journal}

Advances in Medical Education and Practice is an international, peerreviewed, open access journal that aims to present and publish research on Medical Education covering medical, dental, nursing and allied health care professional education. The journal covers undergraduate education, postgraduate training and continuing medical education including emerging trends and innovative models linking education, research, and health care services. The manuscript management system is completely online and includes a very quick and fair peer-review system. Visit http://www.dovepress.com/testimonials.php to read real quotes from published authors. 